\title{
Prevalence of cardiovascular disease among Bangladeshi adult population: a systematic review and meta-analysis of the studies
}

This article was published in the following Dove Press journal:

Vascular Health and Risk Management

\author{
Mohammad Ziaul Islam \\ Chowdhury, ${ }^{1,2}$ Md Ashiqul \\ Haque, ${ }^{2}$ Zaki Farhana, ${ }^{2}$ \\ Ataul Mustufa Anik, ${ }^{2}$ \\ Amadul Hoque \\ Chowdhury, ${ }^{2}$ Sabrina \\ Mahfuja Haque, ${ }^{2}$ Lu-Lu- \\ Wal Marjana, ${ }^{2}$ Piali \\ Dey Bristi, ${ }^{2}$ BM Abu Al \\ Mamun, ${ }^{2}$ Mohammad Jasim \\ Uddin, ${ }^{3}$ Jain Fatema, ${ }^{4}$ Md \\ Meshbahur Rahman, ${ }^{2}$ Tanjila \\ Akter, ${ }^{2}$ Tania Akhter Tani, ${ }^{2}$ \\ Tanvir C Turin ${ }^{1,5}$ \\ 'Department of Community Health \\ Sciences, University of Calgary, \\ Calgary, AB, Canada; ${ }^{2}$ Department \\ of Statistics, Shahjalal University \\ of Science and Technology, Sylhet, \\ Bangladesh; ${ }^{3}$ Department of General \\ Surgery, North East Medical College, \\ Sylhet, Bangladesh; ${ }^{4}$ Department \\ of Clinical Pathology, Sylhet MAG \\ Osmani Medical College Hospital, \\ Sylhet, Bangladesh; ${ }^{5}$ Department of \\ Family Medicine, University of Calgary, \\ Calgary, AB, Canada
}

Correspondence: Mohammad Ziaul Islam Chowdhury

Department of Community Health Sciences, University of Calgary, TRW Building, Third Floor, 3280 Hospital Drive Northwest, Calgary, AB T2N 4Z6, Canada Tel + I 5879172993

Fax +I 4032704329

Email mohammad.chowdhury@ucalgary. ca
Background: Cardiovascular disease (CVD) is a group of conditions affecting the functioning of the heart or blood vessels and is one of the leading causes of death globally. Like other countries, CVD prevalence is also rising among the adults in Bangladesh. Epidemiological studies have shown not only a high CVD prevalence but also a significant increase in its prevalence in Bangladesh in the last few decades. To have a better understanding of the current CVD prevalence scenario, we conducted this systematic review and meta-analysis. Our objective was to assess the prevalence of CVD among the Bangladeshi adult population using evidence from the published scientific literature.

Methods: Electronic databases such as MEDLINE, Embase and PubMed were searched. We also manually checked the references of all relevant publications that describe the prevalence of CVD in Bangladeshi adults. To pool the CVD prevalence, we used random-effects metaanalysis. We assessed heterogeneity using both the formal tests and the subgroup analyses. We also assessed study quality and examined publication bias.

Results: We retrieved 755 potentially relevant papers through searches of electronic and gray literature, of which only 13 met inclusion criteria after the screening and were included in this review. Of the studies that met inclusion criteria, three were carried out in rural populations, five in both urban and rural populations and two in strictly urban populations. Male and female participation in the studies was almost equal. The weighted pooled prevalence of CVD was $5.0 \%$, regardless of the types of CVD, gender and geographical location of the study participants. There was also a high heterogeneity in the observed CVD prevalence. Weighted pooled prevalence of overall CVD in the Bangladeshi population was higher in urban areas $(8 \%)$ compared to rural areas $(2 \%)$. However, no such difference was observed in terms of gender $(3 \%$ for both males and females). The highest reported prevalence (21\%) was for heart disease, while the lowest reported prevalence (1\%) was for stroke. Sources of heterogeneity were often unexplained. The criteria used to assess study quality were fulfilled by only a few studies, and adequate sample size criteria was missed by almost all of them. In addition, there was evidence of small-study effects. Conclusion: A high CVD prevalence along with an upward trend was observed in Bangladeshi adults. Proper strategies are required for primary prevention of CVD so that a further increase can be alleviated and the morbidity and mortality associated with it can be reduced.

Keywords: cardiovascular disease, prevalence, systematic review, Bangladesh

\section{Introduction}

Cardiovascular diseases (CVDs) are among the leading cause of death globally. According to the World Health Organization (WHO), 17.7 million people died from CVDs in 2015 , representing $31 \%$ of all global deaths, ${ }^{1}$ a number that is expected to grow. ${ }^{2,3}$ 
Populations most affected are from low- and middle-income countries like Bangladesh, where $80 \%$ of these deaths occur. ${ }^{3}$ In these countries, the projected cumulative economic losses from all noncommunicable diseases will be $\$ 7.28$ trillion from 2011 to 2025 and CVD will account for nearly half of this projected loss. ${ }^{4}$ Against this backdrop, CVD is considered as a major public health concern worldwide.

Bangladesh has experienced a significant increase in the prevalence of noncommunicable chronic diseases and associated mortality in the last few decades. ${ }^{5,6}$ A rapid urbanization took place in Bangladesh in the past few decades due to its fast economic growth, and recently, it has emerged as a developing country. ${ }^{5,7}$ The results of this growth and urbanization increase the concern that a further rise in the chronic disease burden may be seen due to habituation of a sedentary life style (changing food habits including growing access to and demand for processed food, inconsistent meal times and reduced physical activity). ${ }^{8}$

Population-based surveillance system to track noncommunicable chronic disease is currently absent in Bangladesh. In addition, it is hard to find accurate information on the prevalence of diseases in Bangladesh due to lack of national population-based surveys or central administrative health data. A limited number of studies have been undertaken on the prevalence of CVD in the Bangladeshi population, ${ }^{9-12}$ of which only two discussed the burden of CVD. ${ }^{13,14}$ There is also little research that synthesizes existing studies on the prevalence of CVD through proper systematic review and that assesses overall prevalence and heterogeneity through meta-analysis. The lack of information on the prevalence of CVD restricts health professionals and policy makers from realizing the magnitude of the problem in Bangladesh. To plan and execute preventive strategy for CVD, detailed information about the prevalence of CVD can be very effective and play a vital role. To address this gap, this systematic review and meta-analysis was conducted on data published in the scientific literature to gain a better understanding of the prevalence of CVD in Bangladeshi adult.

\section{Materials and methods Data sources and search strategy}

Electronic databases such as MEDLINE, Embase and PubMed (from inception to April 13, 2017) were searched systematically to identify studies presenting information on the prevalence of CVD among the Bangladeshi adult population. To collect information about other possible studies, the reference lists of all pertinent publications were also searched. We only included studies published in English. The search strategy was based on three key components: CVD, prevalence and Bangladesh. The detailed search strategy is presented in Table 1. In this review, we have used the term "cardiovascular disease (CVD)" according to the $\mathrm{WHO}^{1}$ definition, where CVD includes the following: 1) coronary heart disease (CHD); 2) cerebrovascular disease; 3) peripheral arterial disease; 4) rheumatic heart disease; 5) congenital heart disease; 6) deep vein thrombosis; 7) pulmonary embolism; 8) heart attack and 9) stroke. We defined prevalence as the proportion of a population who have (or

Table I Search strategy used in different databases

\begin{tabular}{|c|c|c|}
\hline MEDLINE & PubMed & Embase \\
\hline I. exp Coronary Disease/ & Search ((Prevalence) AND Bangladesh) & I. exp ischemic heart disease/ \\
\hline 2. Coronary heart disease.mp. & AND $((((()((((c o r o n a r y$ heart disease $)) O R$ & 2. Coronary heart disease.mp. \\
\hline 3. $\exp$ Cerebrovascular Disorders/ & cerebrovascular disease) OR peripheral & 3. exp cerebrovascular disease/ \\
\hline 4. Cerebrovascular disease.mp. & arterial disease) OR rheumatic heart disease) & 4. exp peripheral occlusive \\
\hline 5. exp Peripheral Arterial Disease/ & OR congenital heart disease) OR deep vein & artery disease/ \\
\hline 6. $\exp$ Rheumatic Heart Disease/ & thrombosis) OR pulmonary embolism) OR & 5. exp rheumatic heart disease/ \\
\hline 7. Congenital heart disease.mp. & cardiovascular disease) OR Heart attack) OR & 6. exp congenital heart disease/ \\
\hline 8. exp Venous Thrombosis/ & stroke) & 7. exp deep vein thrombosis/ \\
\hline 9. Deep vein thrombosis.mp. & & 8. exp lung embolism/ \\
\hline 10. exp Pulmonary Embolism/ & & 9. exp cardiovascular disease/ \\
\hline II. exp Cardiovascular Diseases/ & & 10. exp heart infarction/ \\
\hline 12. exp Myocardial Infarction/ & & II. exp cerebrovascular accident/ \\
\hline 13. exp Stroke/ & & 12. I or 2 or 3 or 4 or 5 or 6 or \\
\hline 14. I or 2 or 3 or 4 or 5 or 6 or 7 or & & 7 or 8 or 9 or 10 or 11 \\
\hline 8 or 9 or 10 or 11 or 12 or 13 & & 13. exp prevalence/ \\
\hline 15. exp Prevalence/ & & 14. exp Bangladesh/ \\
\hline 16. exp Bangladesh/ & & 15. 12 and 13 and 14 \\
\hline 17. 14 and 15 and 16 & & \\
\hline
\end{tabular}


had) CVD in a given time period. The summary statistics from the individual studies were prevalence, defined as the number of people in the sample with CVD divided by the total number of people in the sample. Overall prevalence of CVD was defined as the prevalence of all types of CVD together. We defined prevalence of the specific type of CVD (eg, CHD, stroke, congenital heart disease, etc.) separately rather than the combined prevalence.

\section{Study selection}

Potential eligible articles were identified by two reviewers independently using a two-step process. First, titles and abstracts were screened. Abstracts were retained if they were from an original study (no review articles) and presented data on the prevalence of CVD in Bangladesh. At this stage, an abstract was retained when either of the reviewers agreed that it should be or when there was confusion as to qualification based on title and abstract alone. Selected abstracts were screened thereafter on the basis of a full-text review. We tried to deliver a comprehensive systematic review of the topic by considering extensive inclusion criteria. No restriction was imposed on study type (eg, cohort study, cross-sectional study), geographical region (eg, urban, rural) or age ranges. A study was included if the prevalence of CVD was reported in the general adult Bangladeshi population but excluded if the prevalence was reported on individuals with specific diseases (eg, diabetes, hypertension). We excluded non-human studies, studies involving children and other biomedical studies that did not present prevalence of CVD. We measured agreement between reviewers. Any issue related to disagreement between reviewers was solved through consensus.

\section{Data extraction}

The following information was extracted from the included studies: author and publication year, age range of the study participants, gender and number of study participants, area (urban/rural) in which the study was carried out, sample selection procedure, study design, main outcome of the study, criteria used to diagnose CVD and the prevalence of CVD. Data were extracted using a standardized form by two reviewers independently. Each reviewer assessed study quality according to the Joanna Briggs Institute's guide to conducting prevalence and incidence reviews, ${ }^{15,16}$ and these data were extracted from each study for quality assessment purposes: was the sample representative of the target population; were study participants recruited properly; was the sample size sufficient; were the study subjects and setting described elaborately; was the data analysis carried out with adequate coverage of the identified sample; were objective, standard criteria used for measurement of the condition; was the condition measured precisely and were all the important confounding factors/subgroups/differences identified and considered.

\section{Data analysis}

Studies were grouped on the basis of the type of CVD according to outcome and gender and geographical location of the study participants. Random-effects meta-analysis was used to obtain the weighted pooled prevalence with $95 \%$ CIs for studies. A random-effects meta-analysis model assumes that the observed estimates of prevalence (treatment effect) can vary across studies because of both the real differences (heterogeneity) and sampling variability (chance) in the prevalence in each study as opposed to a fixed-effect meta-analysis model where the assumption is that there is no between-study heterogeneity in the true prevalence. ${ }^{17}$

Heterogeneity was determined using Cochran's $Q$ test and the $I^{2}$ statistic and was evaluated using meta-regression and stratified analyses according to the type of CVD and gender and geographical location of the study participants. Cochran's $\mathrm{Q}$ test is the classical measure of heterogeneity measured as the weighted sum of squared differences between individual study prevalence and the pooled prevalence across studies, with the weights being those used in the pooling method. The distribution of Q-statistic is chi square with $m$ (number of studies) minus one degree of freedom. ${ }^{18,19} I^{2}$ measures the percentage of variability in prevalence estimates that is due to between-study heterogeneity rather than chance. ${ }^{18,19}$ Small-study effects were judged applying a funnel plot and Egger's test. Inter-rater reliability was calculated. Stata version 13.1 (StataCorp LP, College Station, TX, USA) was used to perform statistical analysis using the following commands: metaprop, metareg, metabias, metatrim and metafunnel.

\section{Results}

A total of 743 studies on the prevalence of CVD in Bangladesh were identified from our electronic search, and a further 12 potentially relevant papers were revealed in our search of the grey literature. After excluding duplicates and reviewing titles and abstracts, 27 articles were left for full-text screening. Irrelevance with study objective was the main reason for exclusion. Of the 27 articles screened, 14 were removed for the following reasons: two were conducted on individuals with diseases, eight were not an original article (seven review papers and one editorial), one consisted of subjects 
from overall South Asia, one was carried out on children and two were duplicate studies. Therefore, 13 studies were ultimately included for this systematic review. Agreement $(94.23 \%)$ between reviewers on the primary articles eligible for inclusion was good. The article selection process is shown in Figure 1.

A summary outlining the characteristics of the included studies on the prevalence of CVD in Bangladeshi adult population is presented in Table 2. Almost half of the studies were carried out in rural populations (six out of 13). Two studies were carried out on urban populations, three studies in both rural and urban populations and two studies in rural, suburban and urban populations. Different types of CVD were reported: six studies reported stroke, two ischemic heart disease (IHD), one CVD, two CHD, one congenital heart disease, two heart disease, one heart attack and one angina pectoris. Both genders were represented in all studies. Study design was cross-sectional in nine studies, prospective observational in one study and multistage prospective in one study. One study was conducted in two phases, with the first phase being over a 10-year period, and one study did not report the study design. Samples were selected using a simple random sampling procedure in only three studies, and four studies did not report the sample selection procedure.

The studies included in the present systematic review comprised 129,740 subjects, $50.96 \%$ of whom were men and $49.04 \%$ women. The age of the participants was $\geq 20$ years in most studies. Prevalence of CVD was recorded by all the studies and ranged from $0.062 \%$ to $77.7 \%$. Only one study ${ }^{10}$ recorded age-adjusted prevalence of CVD. The rest of the studies recorded overall prevalence, gender-specific and geographical location-specific prevalence and prevalence of specific types of CVD.

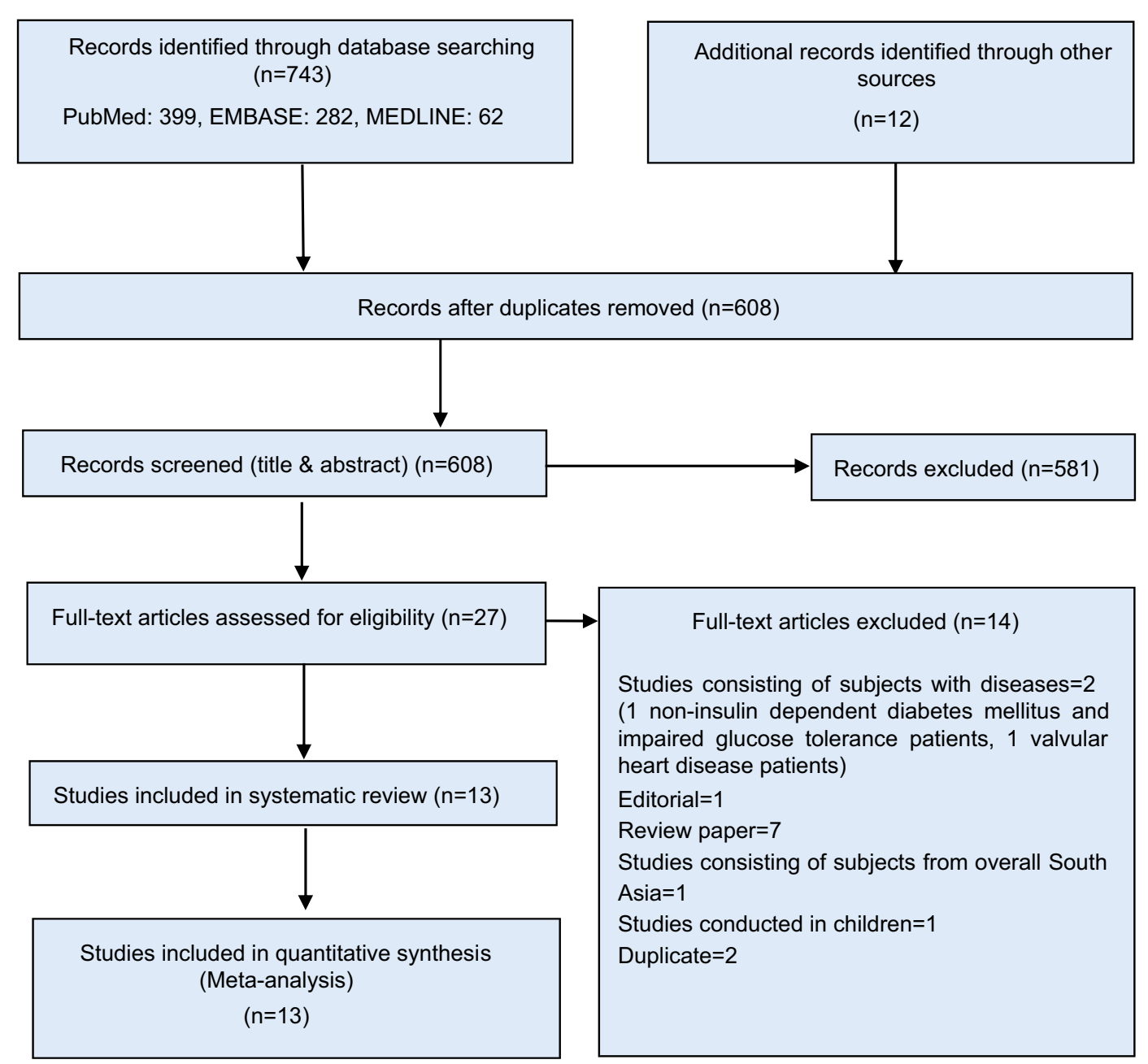

Figure I PRISMA diagram for systematic review of studies that evaluated the prevalence of CVD in the Bangladeshi population. Abbreviation: CVD, cardiovascular disease; PRISMA, Preferred Reporting Items for Systematic Reviews and Meta-Analyses. 


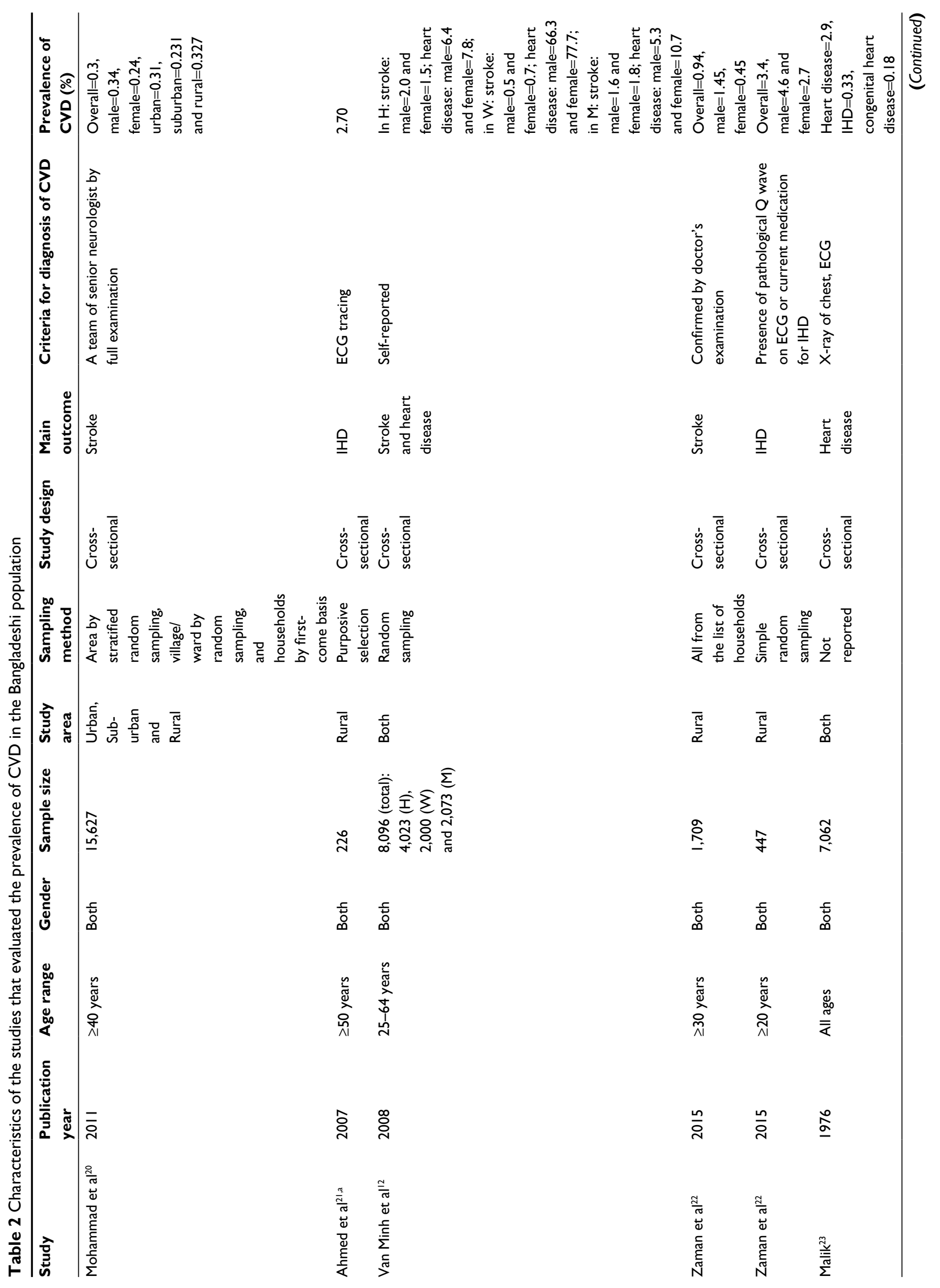




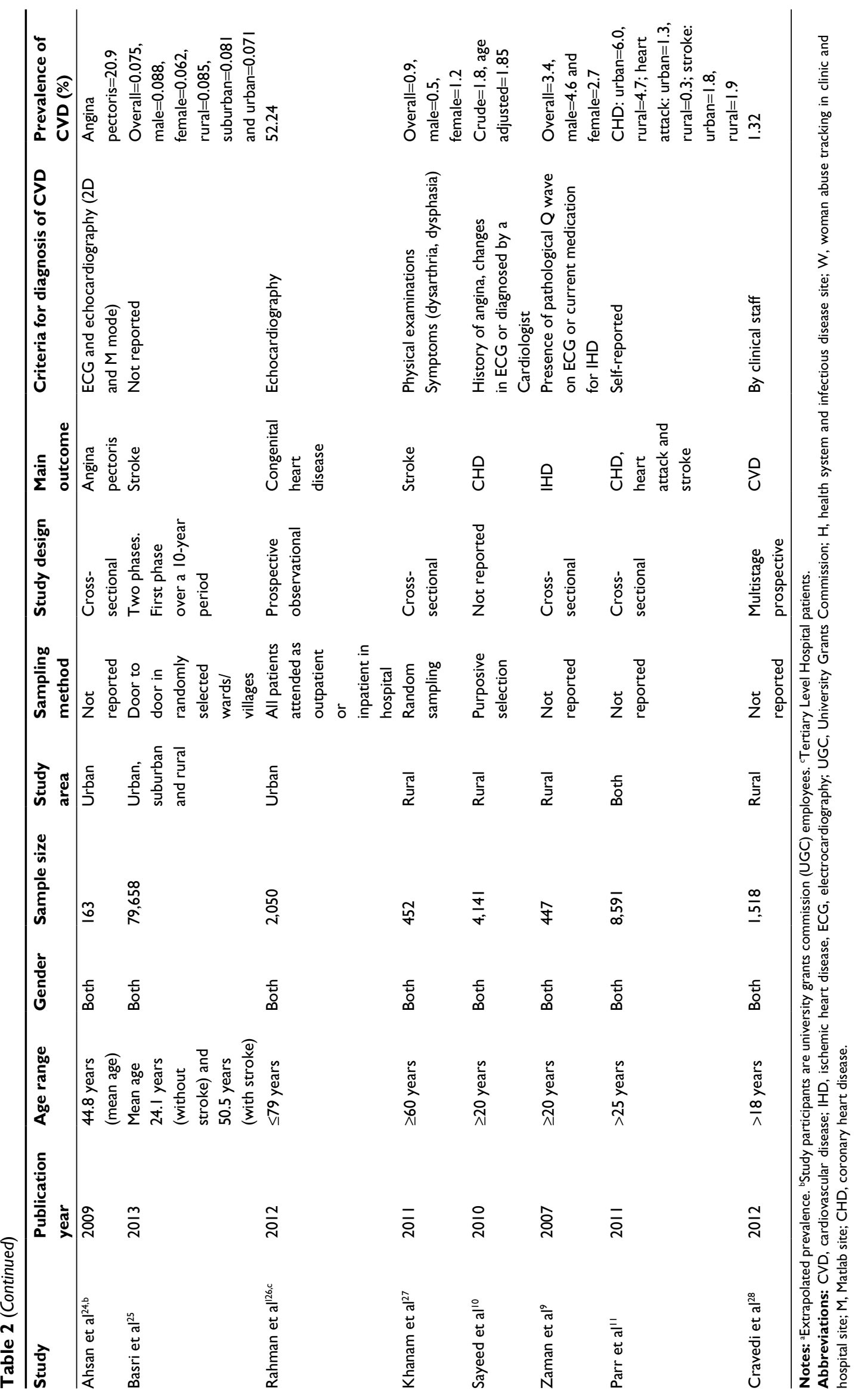


The weighted pooled prevalence of CVD regardless of gender and geographical location of the study participants and the types of CVD reported was $5.0 \%(95 \% \mathrm{CI}$ : $3 \%-9 \%)$. Severe heterogeneity was observed in the prevalence of CVD ( $I^{2}=99.78 \%$; Cochran's Q-statistic $p<0.001$; Figure 2). Meta-regression failed to identify gender (male vs female, $p=0.881$ ) and geographical location (urban vs rural, $p=0.094$ ) of the study participants as a probable source of heterogeneity in the overall CVD prevalence. In addition, the joint tes $\mathrm{t}^{29}$ of CVD types after adjusting for gender $(p=0.069)$ and after adjusting for geographical location $(p=0.070)$ of the study participants did not show any evidence that the prevalence differed among the types of CVD reported in the studies.

\section{Subgroup analysis based on the gender of study participants}

Although initial overall tests for heterogeneity based on gender of the study participants were nonsignificant $(p=0.881)$, gender differences existed in CVD prevalence due to differences in genetic and psychosocial risk factors in men and women. ${ }^{30-32}$ As such, a subgroup analysis according to the gender of the study participants was performed to explore any possible differences in CVD prevalence (Figure 3).

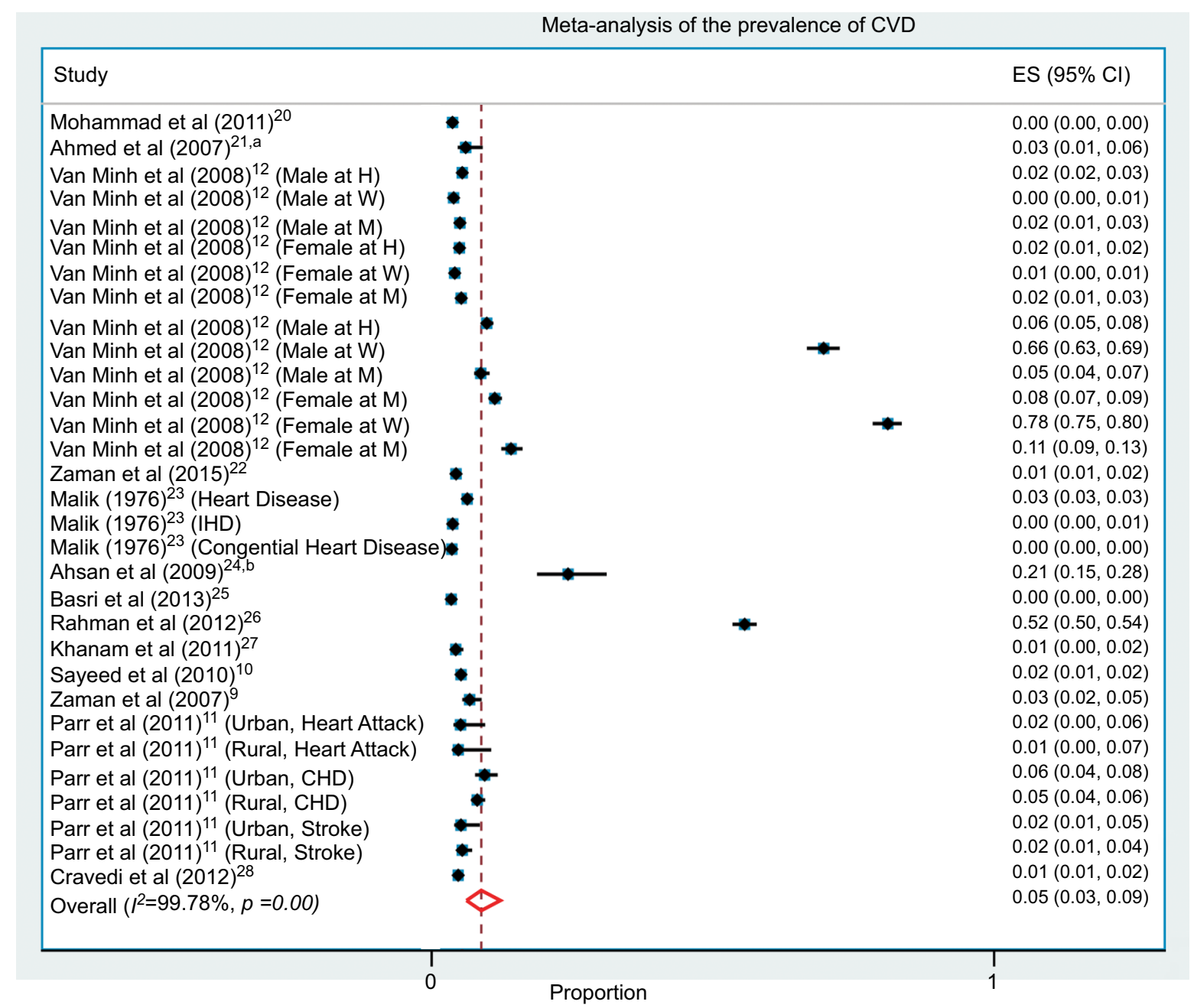

Figure 2 Forest plot of prevalence, with $95 \% \mathrm{Cls}$ of CVD in Bangladeshi population.

Notes: aExtrapolated prevalence was reported. 'Study participants are UGC employees.

Abbreviations: CVD, cardiovascular disease; UGC, University Grants Commission; ES, effect size; H, health system and infectious disease site; W, woman abuse tracking in clinic and hospital site; M, Matlab site; IHD, ischemic heart disease; CHD, coronary heart disease. 
Weighted pooled prevalence of CVD was the same in both females (3\% [95\% CI: $1 \%-7 \%])$ and males (3\% [95\% CI: $1 \%-6 \%])$. A severe unexplained between-study heterogeneity $\left(I^{2}=99.73 \%\right.$; Cochran's Q-statistic $p<0.001$; Figure 3$)$ in the prevalence of CVD was observed when study participants were female only. Meta-regression failed to identify geographical location of the study participants (urban vs rural, $p=0.321$ ) or the CVD types (joint test, $p=0.109$ ) after adjusting for geographical location of the study participants as the source of heterogeneity. In addition, a severe unexplained between-study heterogeneity $\left(I^{2}=99.64 \%\right.$; Cochran's Q-statistic $p<0.001$; Figure 3 ) in the prevalence of CVD was observed when study participants were male only. Meta-regression again failed to identify geographical location of the study participants (urban vs rural, $p=0.311$ ) or the CVD types (joint test, $p=0.118088$ ) after adjusting for geographical location of the study participants as the source of heterogeneity.

\section{Subgroup analysis based on the geographical location of study participants} The prevalence of CVD and associated risk factors could vary substantially in urban and rural areas, particularly in developing countries like Bangladesh, due to differences

Meta-analysis of the prevalence of CVD

(Stratified according to the gender of the participants)

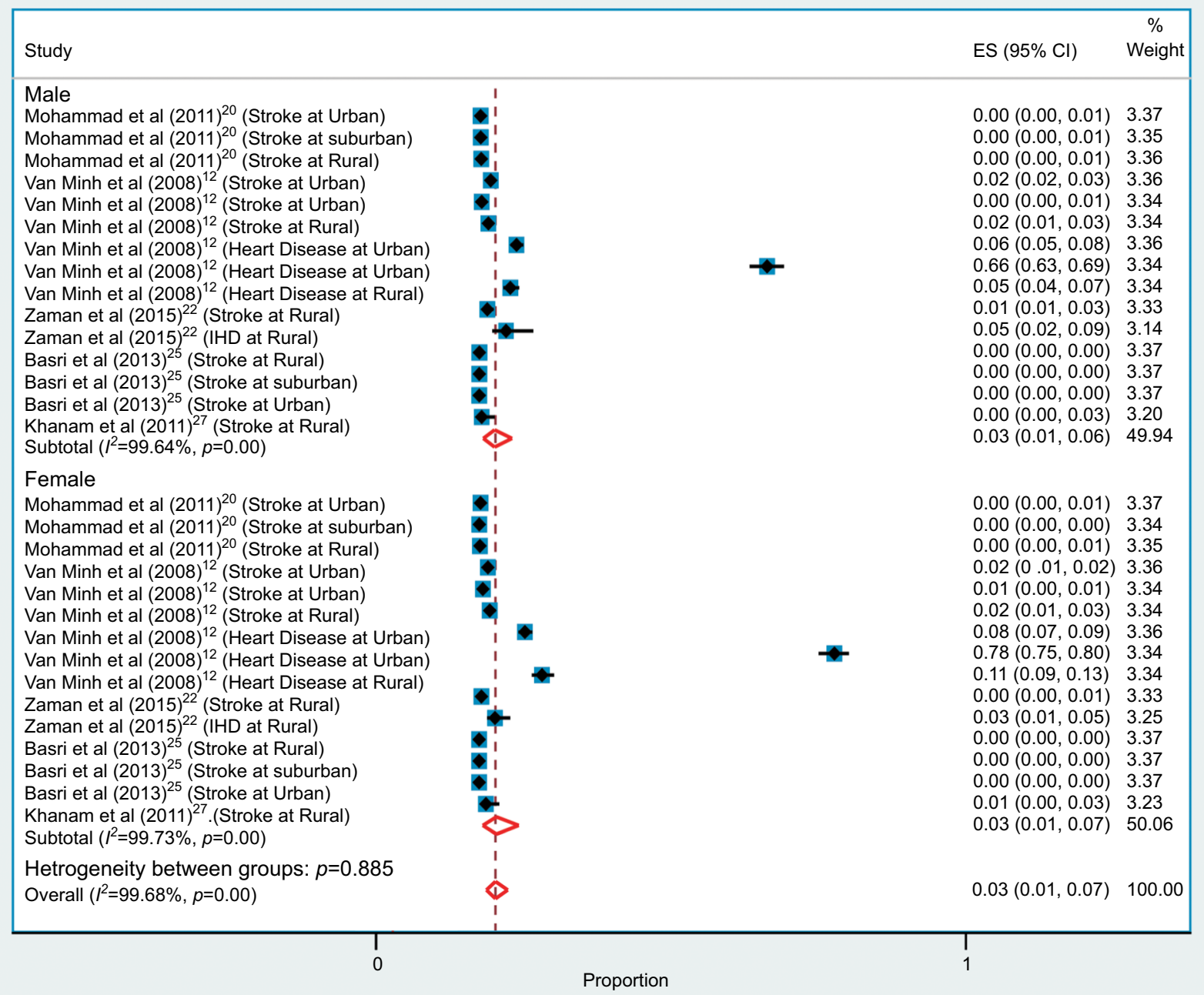

Figure 3 Forest plot of prevalence, with $95 \%$ Cls of CVD in Bangladeshi population, stratified according to the gender of study participants. Abbreviations: CVD, cardiovascular disease; ES, effect size. 
in lifestyles, which was clearly evident from the study. ${ }^{33}$ Although initial overall tests for heterogeneity based on geographical location (urban vs rural, $p=0.094$ ) were nonsignificant, we carried out a subgroup analysis according to the geographical location of the study participants to explore any possible differences in CVD prevalence (Figure 4). Weighted pooled prevalence of CVD was higher in urban areas ( $8 \%$ [95\% CI: $3 \%-14 \%])$ compared to rural areas (2\% [95\% CI: $1 \%-4 \%])$. A severe between-study heterogeneity $\left(I^{2}=99.87 \%\right.$; Cochran's Q-statistic $p<0.001$; Figure 4$)$ in the prevalence of CVD was observed when study participants were from urban areas only. Meta-regression failed to identify the gender of the study participants (male vs female, $p=0.903$ ) as the source of heterogeneity but did identify CVD types (joint test, $p=0.028$ ) after adjusting for gender of the study participants as the source of heterogeneity. In addition, a severe between-study heterogeneity $\left(I^{2}=98.12 \%\right.$; Cochran's Q-statistic $p<0.001$; Figure 4 ) in the prevalence of CVD was observed when study participants were from rural areas only. Meta-regression again failed to identify the

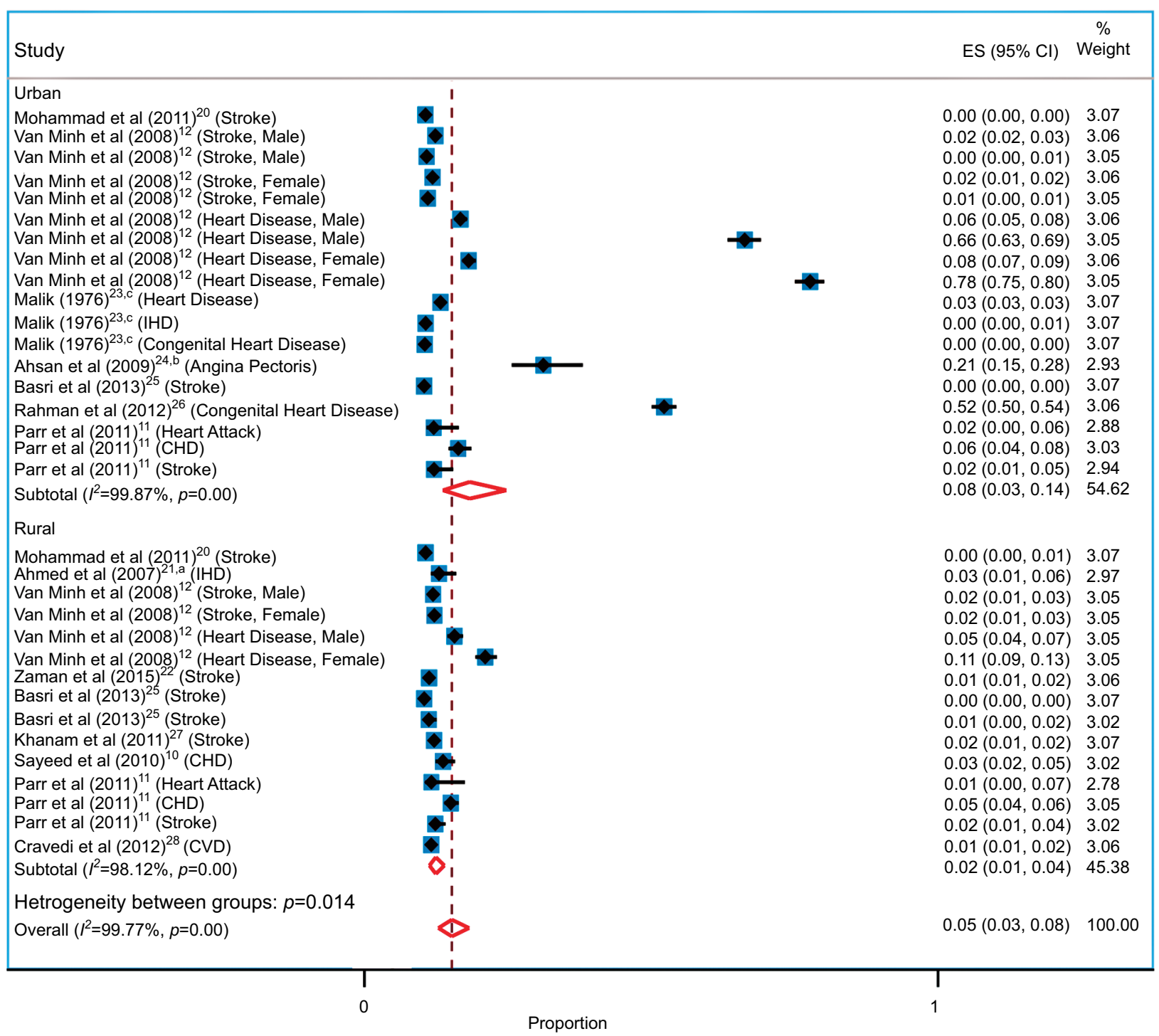

Figure 4 Forest plot of prevalence, with $95 \% \mathrm{Cls}$ of CVD in Bangladeshi population, stratified according to the geographical region of study participants.

Notes: a Extrapolated prevalence was reported. 'Study participants are UGC employees. 'Most study participants are from urban areas and so were treated as urban residents in the analysis.

Abbreviations: CVD, cardiovascular disease; UGC, University Grants Commission; ES, effect size; IHD, ischemic heart disease; CHD, coronary heart disease. 
gender of the study participants (male vs female, $p=0.776$ ) as the source of heterogeneity but did identify CVD types (joint test, $p=0.011$ ) after adjusting for gender of the study participants as the source of heterogeneity.

\section{Subgroup analysis based on the types of CVD}

It is very well known that the prevalence of CVD varies depending on the type of CVD considered in studies. Hence, the differences in the types of CVD included in the studies in the present analysis makes meaningful pooling of CVD prevalence difficult and could be a major source of heterogeneity. To further explore heterogeneity, we carried out a subgroup analysis by dividing the studies according to the type of CVD reported (Figure 5).

Our review identified 13 studies describing eight different types of CVD (stroke, IHD, heart disease, angina pectoris, congenital heart disease, CHD, heart attack and CVD)

Meta-analysis of the prevalence of CVD

(stratified by cardiovascular disease type)

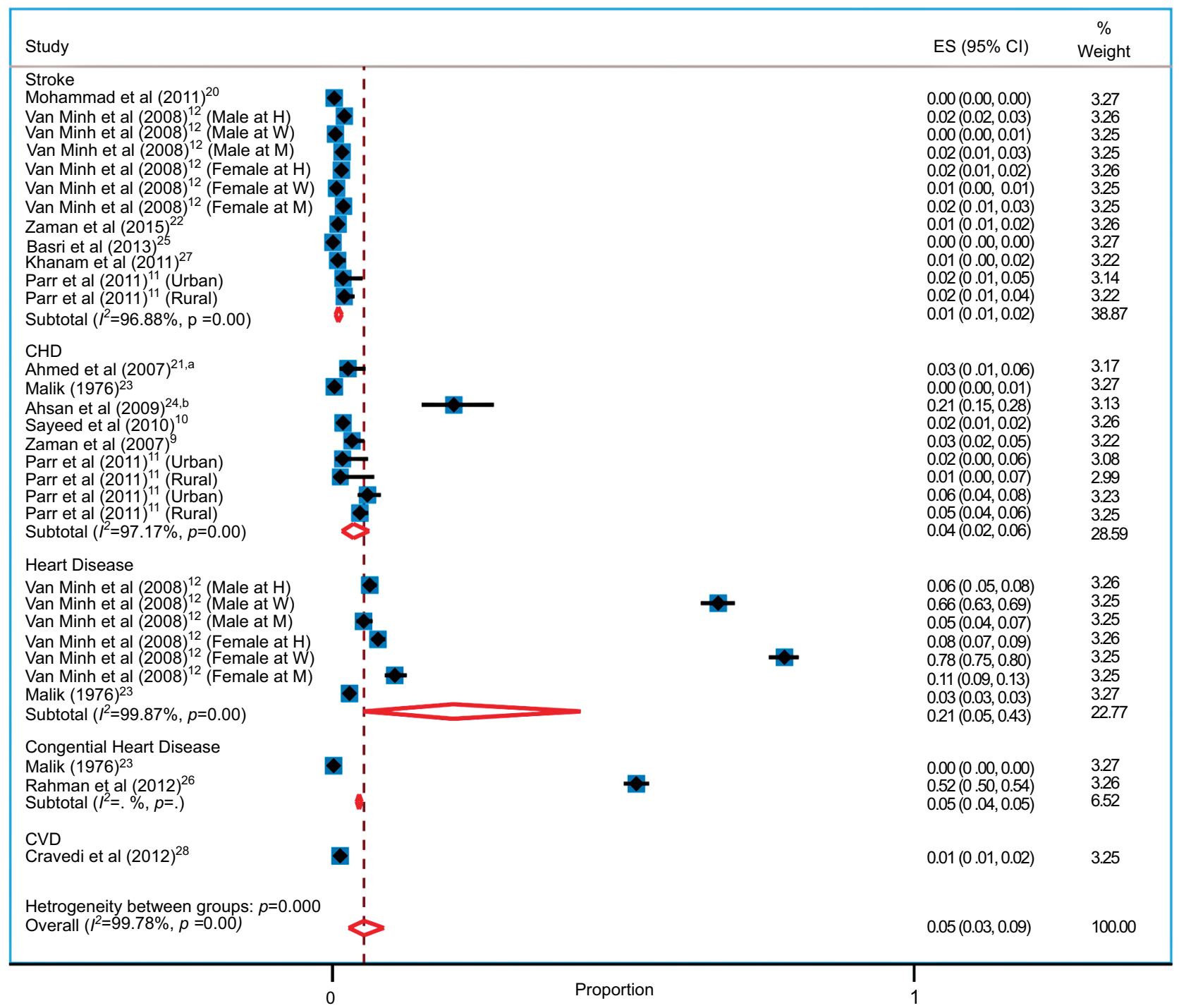

Figure 5 Forest plot of prevalence, with 95\% Cls of CVD in Bangladeshi population, stratified according to the type of CVD reported. Notes: axtrapolated prevalence was reported. 'Study participants are UGC employees.

Abbreviations: CVD, cardiovascular disease; UGC, University Grants Commission; ES, effect size; CHD, coronary heart disease; H, health system and infectious disease site; W, woman abuse tracking in clinic and hospital site; M, Matlab site. 
prevalence. Although our search, which was undertaken according to the WHO definition of CVD, included nine different types of CVD, some CVD types (eg, rheumatic heart disease) were not identified. Not finding any prevalence studies on rheumatic heart disease in the adult population was unexpected, despite the fact that a large proportion of Bangladeshi population suffers from malnutrition and lives in unhygienic conditions, both of which are related with the development of this disease. We then grouped available CVD types into five major CVD categories (stroke, CHD, heart disease, congenital heart disease and CVD) based on their clinical manifestation. We treated IHD, angina pectoris and heart attack as CHD while grouping, since IHD consists principally of CHD and angina pectoris and heart attack are the major clinical manifestations of CHD. ${ }^{34}$

Among the studies that recorded the prevalence of stroke, weighted pooled prevalence of stroke was $1 \%(95 \% \mathrm{CI}$ : $1 \%-2 \%$ ) with unexplained significant severe heterogeneity between studies ( $I^{2}=96.88 \%$; Cochran Q-statistic $p<0.001$; Figure 5). Meta-regression did not find gender (male vs female, $p=0.644$ ) and the geographical location (urban vs rural, $p=0.689$ ) of the study participants to be responsible for the heterogeneity between the studies in this subgroup.

In the studies that recorded the prevalence of CHD, weighted pooled prevalence of CHD was $4 \%$ (95\% CI: $2 \%-6 \%$ ) with unexplained significant severe heterogeneity between studies ( $I^{2}=97.17 \%$; Cochran Q-statistic $p<0.001$; Figure 5). Meta-regression did not find the geographical location (urban vs rural, $p=0.440$ ) of the study participants to be responsible for the heterogeneity between the studies in this subgroup. Most of the studies reported overall prevalence of CHD rather than gender-specific prevalence, which restricted performing meta-regression based on gender in the CHD subgroup. Individually, the CVD types that comprised the CHD category had different prevalence. The weighted pooled prevalence of IHD was $2 \%$, that of CHD was $4 \%$ and that of heart attack was $2 \%$. Only one study reported $21 \%$ prevalence of angina pectoris.

Two studies described heart disease prevalence; however, the definition of heart disease was not clear in either study. ${ }^{12,23}$ Van Minh et a ${ }^{12}$ did not provide a definition of what they meant by heart disease. Malik ${ }^{23}$ also did not provide any formal definition of heart disease; however, he indicated the distribution of various conditions in individuals with heart disease, which included hypertension, rheumatic valvular disease, IHD, cardiac arrhythmia, congenital heart disease, cardiomyopathy and cor pulmonale. The weighted pooled prevalence of heart disease in these two studies was $21 \%$
(95\% CI: 5\%-43\%) with unexplained significant high heterogeneity between studies ( $I=99.87 \%$; Cochran Q-statistic $p<0.001$; Figure 5). Meta-regression did not find gender (male vs female, $p=0.852$ ) and the geographical location (urban vs rural, $p=0.329$ ) of the study participants to be responsible for the heterogeneity between the studies in the heart disease subgroup.

Weighted pooled prevalence of congenital heart disease was 5\% (95\% CI: $4 \%-5 \%)$. As only two studies reported prevalence of congenital heart disease, heterogeneity was not assessed. CVD was reported by only one study, with $1 \%$ (95\% CI: 1\%-2\%) prevalence being observed.

\section{Assessment of temporal change in CVD prevalence}

To assess the temporal change in CVD prevalence, we performed meta-regression on CVD prevalence over the study year. Overall prevalence of CVD increased by $0.12 \%$ ( $p=0.71$; Figure 6A) for every 1 year increase in study year, suggesting that the prevalence of CVD is on the rise. The increase in CVD prevalence over the study year was not similar in different CVD types (Figure 6B). The increase in CVD prevalence was higher for congenital heart disease compared to other CVD types. For stroke, the prevalence was quite stable over time, although the time span was short (2008-2015). For CVD, it was not possible to observe temporal change due to the availability of only one study.

\section{Study quality assessment}

Study quality was evaluated using criteria set out in the Joanna Briggs Institute's guide to conducting prevalence and incidence reviews ${ }^{15,16}$ and is outlined in Table 3 . A set of eight criteria was used to evaluate study quality. The sample represented the target population in all studies. Study participants were enrolled appropriately in six (46\%) studies. The sample size was sufficient in only one (8\%) study. Study participants and setting were described elaborately in six (46\%) studies. Data analysis was carried out with reasonable coverage of the identified sample in four (31\%) studies. An objective, standard criterion was used to precisely measure the conditions in eight (62\%) and seven (54\%) studies considered as major confounding factors and subgroups.

\section{Publication bias}

The funnel plot indicated the presence of asymmetry and publication bias (Figure 7), and Egger's test $(p=0.001)$ confirmed the existence of small-study effects, in which small-sized studies reported a higher prevalence of CVD. We applied 
A

Overall prevalence of CVD over the time

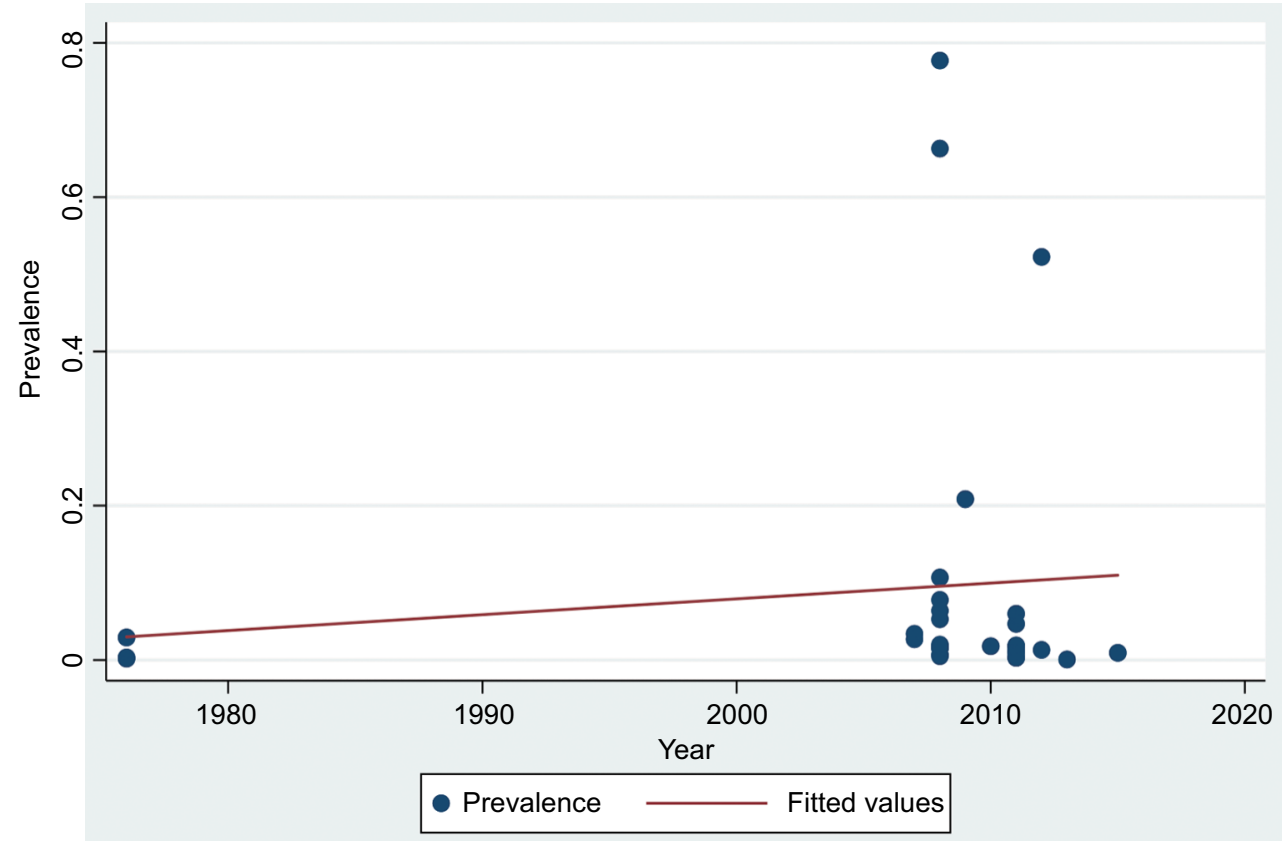

B

Prevalence of CVD over the time

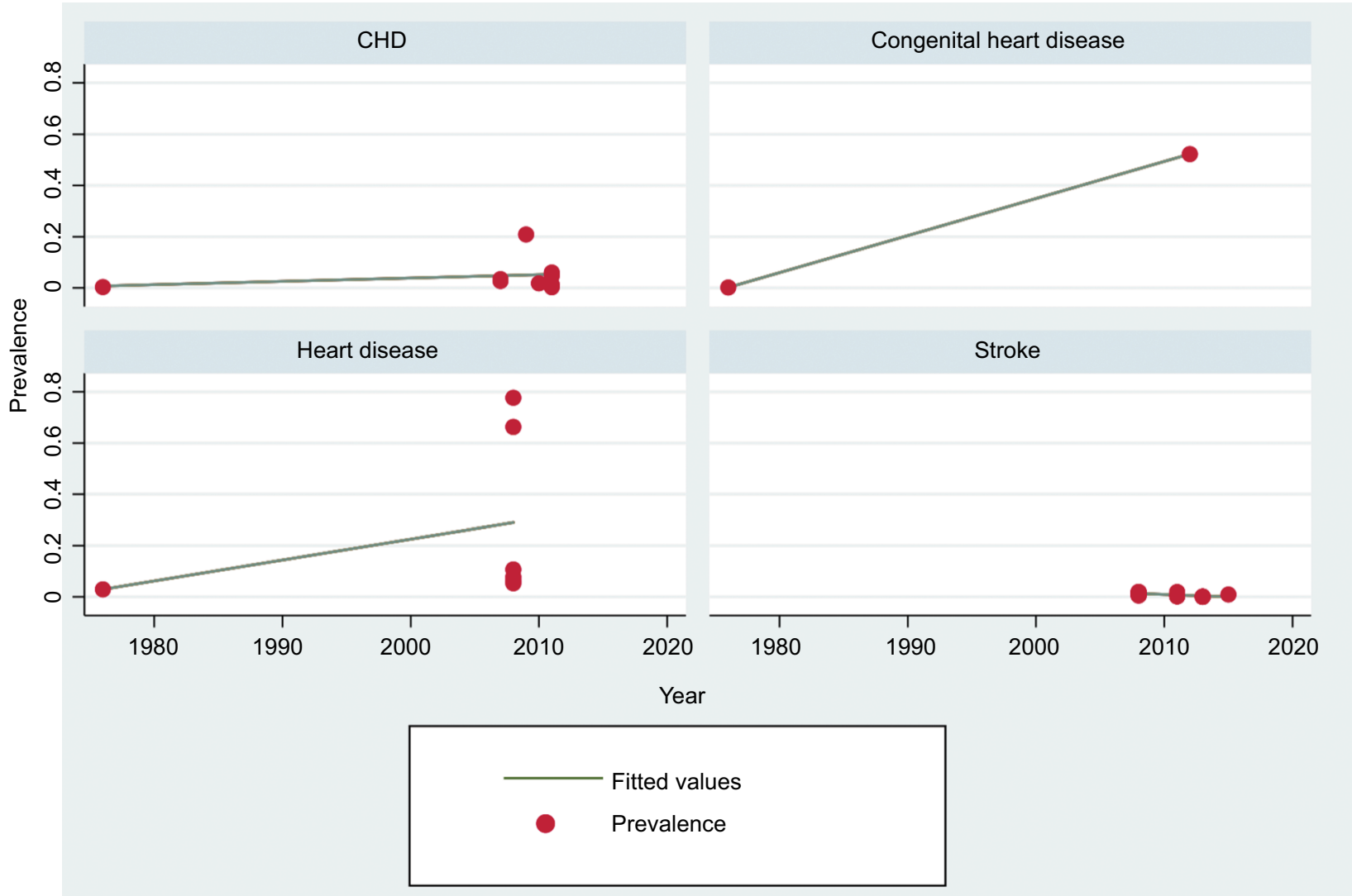

Figure 6 (A) Prevalence of CVD in Bangladesh over the time and (B) prevalence of CVD in Bangladesh over the time (stratified by the CVD type). Abbreviations: CVD, cardiovascular disease; $\mathrm{CHD}$, coronary heart disease. 
Table 3 Study quality assessment of studies that evaluated the prevalence of CVD in the Bangladeshi population

\begin{tabular}{|c|c|c|c|c|c|c|c|c|}
\hline Study & $\begin{array}{l}\text { Was the } \\
\text { sample } \\
\text { representative } \\
\text { of the target } \\
\text { population? }\end{array}$ & $\begin{array}{l}\text { Were study } \\
\text { participants } \\
\text { recruited } \\
\text { in an } \\
\text { appropriate } \\
\text { way? }\end{array}$ & $\begin{array}{l}\text { Was the } \\
\text { sample } \\
\text { size } \\
\text { adequate? }\end{array}$ & $\begin{array}{l}\text { Were } \\
\text { the study } \\
\text { subjects } \\
\text { and } \\
\text { setting } \\
\text { described } \\
\text { in detail? }\end{array}$ & $\begin{array}{l}\text { Is the data } \\
\text { analysis } \\
\text { conducted } \\
\text { with } \\
\text { sufficient } \\
\text { coverage } \\
\text { of the } \\
\text { identified } \\
\text { sample? }\end{array}$ & $\begin{array}{l}\text { Were } \\
\text { objective, } \\
\text { standard } \\
\text { criteria } \\
\text { used for } \\
\text { measurement } \\
\text { of the } \\
\text { condition? }\end{array}$ & $\begin{array}{l}\text { Was the } \\
\text { condition } \\
\text { measured } \\
\text { reliably? }\end{array}$ & $\begin{array}{l}\text { Are all the } \\
\text { important } \\
\text { confounding } \\
\text { factors/ } \\
\text { subgroups/ } \\
\text { differences } \\
\text { identified and } \\
\text { accounted } \\
\text { for? }\end{array}$ \\
\hline $\begin{array}{l}\text { Mohammad } \\
\text { et al }(201 \mathrm{I})^{20}\end{array}$ & Yes & Yes & Not clear & No & Not clear & Yes & Yes & Yes \\
\hline $\begin{array}{l}\text { Ahmed et al } \\
(2007)^{21}\end{array}$ & Yes & No & Not clear & Yes & No & Not clear & Yes & No \\
\hline $\begin{array}{l}\text { Van Minh et } \\
\text { al }(2008)^{12}\end{array}$ & Yes & Yes & Not clear & Yes & Not clear & Yes & Not clear & Yes \\
\hline $\begin{array}{l}\text { Zaman et al } \\
(2015)^{22}\end{array}$ & Yes & Yes & Not clear & No & Yes & Yes & Not clear & No \\
\hline $\begin{array}{l}\text { Zaman et al } \\
(2015)^{22}\end{array}$ & Yes & Yes & Not clear & Yes & No & Yes & Yes & Yes \\
\hline Malik $(1976)^{23}$ & Yes & No & Not clear & No & Not clear & Not clear & Yes & Yes \\
\hline $\begin{array}{l}\text { Ahsan et al } \\
(2009)^{24}\end{array}$ & Yes & Not clear & Not clear & No & Yes & Not clear & Yes & No \\
\hline $\begin{array}{l}\text { Basri et al } \\
(2013)^{25}\end{array}$ & Yes & Not clear & Not clear & No & Not clear & Yes & Not clear & Yes \\
\hline $\begin{array}{l}\text { Rahman et al } \\
(2012)^{26}\end{array}$ & Yes & Yes & Not clear & No & Yes & Yes & Yes & Yes \\
\hline $\begin{array}{l}\text { Khanam et al } \\
(201 \mathrm{II})^{27}\end{array}$ & Yes & Yes & Not clear & No & No & Yes & Yes & No \\
\hline $\begin{array}{l}\text { Sayeed et al } \\
(2010)^{10}\end{array}$ & Yes & No & Not clear & Yes & Not clear & Yes & Yes & Yes \\
\hline $\begin{array}{l}\text { Zaman et al } \\
(2007)^{9}\end{array}$ & Yes & Yes & Not clear & Yes & Not clear & Yes & Yes & Yes \\
\hline $\begin{array}{l}\text { Parr et al } \\
(2011)^{\prime \prime}\end{array}$ & Yes & Not clear & Yes & Yes & Yes & No & No & No \\
\hline $\begin{array}{l}\text { Cravedi et al } \\
(2012)^{28}\end{array}$ & Yes & Not clear & Not clear & Yes & Not clear & Not clear & Not clear & No \\
\hline
\end{tabular}

Abbreviation: CVD, cardiovascular disease.

a trim and fill method ${ }^{35,36}$ as a form of sensitivity analysis to see how bias in the pooled estimates could be reduced. We obtained an overall $0.4 \%$ adjusted pooled prevalence of CVD with the fixed-random-effects trim and fill model. According to Peters et al, ${ }^{37}$ a fixed-random-effects trim and fill model performs better (is least biased) than other trim and fill models in our context (large between-study heterogeneity and publication bias). According to this model, 16 studies were assumed to be missing, which was adjusted for in the fixed-random-effects trim and fill model. This resulted in what appeared to be a large difference in unadjusted and adjusted overall CVD prevalence estimates (5\% vs $0.4 \%$ ). Funnel plot asymmetry can be due to many reasons other than publication bias. We also do not know with any certainty that publication bias is the true cause of funnel plot asymmetry. As such, we remained cautious in interpreting this adjusted pooled prevalence estimate. This adjusted pooled estimate may not represent an accurate summary of the evidence base and can be misleading in reflecting true prevalence of CVD.

\section{Discussion}

This systematic review and meta-analysis gives summary estimates for the prevalence of CVD in the Bangladeshi adult population. The findings of this review suggest that the weighted pooled prevalence of CVD is between $1 \%$ and $21 \%$ depending on the type of CVD reported by studies. The highest pooled prevalence $(21 \%)$ was reported for heart disease, while the lowest pooled prevalence (1\%) was 


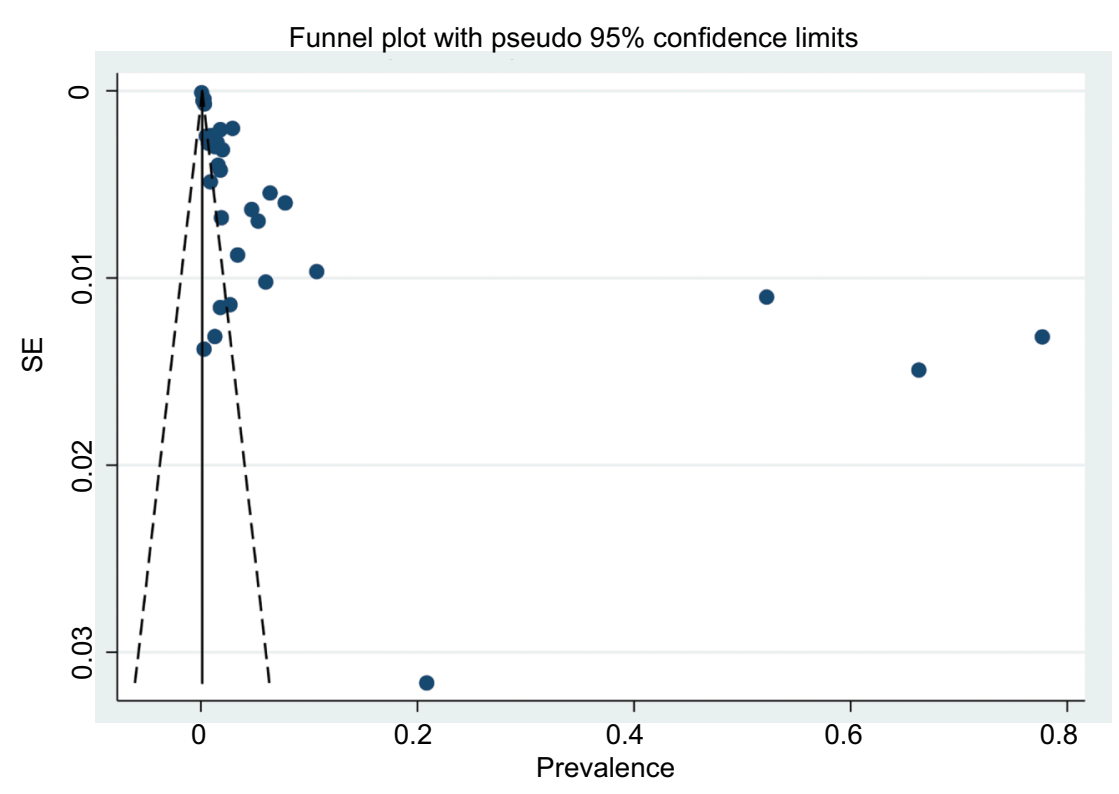

Figure 7 Funnel plot for the publication bias of the studies that evaluated the prevalence of CVD in Bangladeshi population. Abbreviations: CVD, cardiovascular disease; SE, standard error.

reported for stroke. The observed overall pooled prevalence of CVD regardless of the type of CVD was 5\% in Bangladesh. Differences in the prevalence in different types of CVD are mainly due to the nature of each CVD type. The observed weighted pooled prevalence of CHD and congenital heart disease was quite similar. There can be few reasons for the relatively low stroke prevalence. The short duration of stroke illness, its low incidence, the challenges associated with the diagnosis of stroke that are mainly due to the cost and availability of tests (eg, computed tomography [CT] scans and magnetic resonance imaging [MRI], which are expensive and not available in most rural areas) and low survival after an acute event (due to lack of proper treatment facilities, particularly in rural areas) can potentially be attributed to the low prevalence of stroke in Bangladesh. Conversely, a high prevalence of heart disease was observed. Although such a high prevalence of heart disease is based on only two studies, we could not identify potential causes for that. The definition of heart disease was absent in one study, while several conditions were considered in defining heart disease in the other study. Including such conditions in the definition of heart disease can potentially inflate its prevalence.

We saw mixed results when we compared our findings with reports from other regions. The crude prevalence of CHD in the urban and rural areas of neighboring India was reported to be from $1.04 \%$ to $13.21 \%$ and $1.60 \%$ to $7.43 \%$, respectively. ${ }^{38}$ The same study reported an age-adjusted prevalence of stroke in urban and rural areas of India of $0.33 \%-0.42 \%$ and $0.08 \%-0.26 \%$ respectively. ${ }^{38}$ The overall prevalence of heart attack and stroke was reported to be $6.2 \%$ and $2.6 \%$, respectively, in Pakistan. ${ }^{39}$ The prevalence of stroke was reported to be $1.04 \%,{ }^{40}$ and age- and gender-standardized prevalence of IHD was reported to be $9.3 \%$ in Sri Lanka. ${ }^{41}$ Prevalence of CVD in Nepal was reported to be $5.7 \% \%^{42}$ and that of coronary artery disease was reported to be $5 \%{ }^{43} \mathrm{~A}$ population-based study of ethnic groups in Canada reported 10.7\% prevalence of any CVD among South Asians, 2.4\% prevalence of any CVD among Chinese and $5.4 \%$ prevalence of any CVD among Europeans. ${ }^{44}$ The same study reported $1 \%$ prevalence of stroke among South Asians, $2 \%$ prevalence of stroke among Chinese and 6\% prevalence of stroke among Europeans. ${ }^{44}$

This study demonstrated that the weighted pooled prevalence of overall CVD in the Bangladeshi population is higher in urban areas $(8 \%)$ compared to rural areas (2\%). However, no such difference was observed in terms of gender. The weighted pooled prevalence of overall CVD was the same and was observed to be $3 \%$ in both males and females. The underlying factors behind the increased prevalence of CVD in urban populations could be multifarious. The prevalence of CVD could depend on several factors, including lifestyle, diet, environmental factors, and other population-specific risk factors. In developing countries like Bangladesh, people who live in urban areas have a different lifestyle and dietary pattern 
than those who live in rural areas. Urban residents have a more sedentary lifestyle than rural residents, who are often involved with heavy physical activity, and this difference contributes significantly to CVD prevalence. Differences in food supply and consumption patterns in urban areas and limited food diversity in rural areas influence dietary patterns and thus the status of CVD prevalence. Furthermore, urban residents are exposed to different environmental conditions (eg, access to physical activity facilities, better transportation, lack of open spaces and exposure to air pollution) than those who reside in rural areas. In general, the prevalence of CVD in Bangladesh is on the rise. The underlying factors behind the increased prevalence of CVD in the Bangladeshi population could be many. However, a geographical change in disease patterns from communicable to noncommunicable diseases, a growing trend of urbanization and an attraction for following a Western lifestyle could influence such increased CVD prevalence. ${ }^{45,46}$

Our findings suggest an increasing prevalence of CVD in Bangladesh. With the rapid urbanization in the last 2 decades, substantial socioeconomic and demographic changes have occurred in Bangladesh, which are likely to increase CVD prevalence and the morbidity and mortality associated with it in the future. It is believed that such urbanization is associated with several risk factors for CVD, such as less physical activity, an unhealthy diet, increased stress and anxiety and changes in behavioral factors, all of which contribute to an increasing CVD prevalence. CVD and its risk factors are a major cause of premature death and chronic disability in Bangladesh and account for $13.4 \%$ of disability-adjusted life years (DALYs) lost there. ${ }^{47}$ This rising burden of CVD demonstrates the importance of increased effort in the prevention and treatment of it in Bangladesh.

We noticed high between-study heterogeneity among the studies. In an attempt to explore possible sources of heterogeneity, we carried out a subgroup analysis according to study area (urban/rural), gender (male/female) and CVD type (stroke/CHD/heart disease/congenital heart disease). Heterogeneity was still noticed within the subgroups, and often, we failed to locate the source of heterogeneity within the subgroups.

We detected evidence of small-study effect $(p=0.001)$, in which small-sized studies reported a higher prevalence of CVD. In addition, the asymmetry on the funnel plot clearly demonstrated the presence of publication bias. Study quality evaluation indicates that almost all the studies failed to meet the criteria of "adequate sample size" for their studies. Also in many studies, data analysis was performed without adequate coverage of the identified sample, a point to be noted.
The biggest strength of the present study is the comprehensiveness of the process, which included a search of three different databases, explicit inclusion/exclusion criteria, and a wide-ranging use of reference lists. Thus, it is very unlikely that any pertinent studies have been missed. Nevertheless, there are several limitations to our study. We only considered papers published in English and failed to consider very local journals that are not available through the major academic databases. Most of the studies identified in our review and included in the meta-analysis addressed very selected populations. In addition, the existence of publication bias in the selected studies may impair validity of pooling CVD prevalence estimates. These limitations may generate possible sampling bias and could potentially restrict the generalizability of our study results to the entire Bangladeshi population. The methodology used to define CVD conditions was also heterogeneous and not standard in most studies. Additionally, lack of uniform definitions of CVD, variance in the age groups included and the settings in the studies included in this review could result in restrictions in comparability.

\section{Conclusion}

We believe our review is the first of its kind that systematically assessed the scientific literature on the prevalence of CVD in Bangladeshi adults and has attempted to provide a comprehensive report on study variability in the reported prevalence. According to our review, despite differences in CVD type, gender, age and geographical area of the participants studied, the prevalence of CVD is high, particularly in urban areas, and is rising in Bangladesh, and immediate action from both a clinical and a public health standpoint is recommended. Many of the studies identified in the present systematic review consist of datasets that are small and specific to the particular settings (eg, hospital patients or employees of an institution) or regions and indicate a lack of nationally representative data on the prevalence of CVD in Bangladesh. Well-designed, population-based, nationally representative surveys focusing on CVD and its associated risk factors are crucial to identify the severity of CVD prevalence in Bangladesh, to implement preventive strategies to alleviate further increase in the prevalence and to reduce the morbidity and mortality associated with CVD. It is also crucial to examine potential risk factors that need to be addressed, especially those related to lifestyle. Furthermore, it is also necessary to increase public awareness of the high prevalence of CVD and its associated risk factors including education programs on diet and healthier lifestyles. A proper understanding and information of these factors may 
be helpful in tracking CVD and could play a part in designing prevention strategies to confront this issue.

\section{Acknowledgment}

This research did not receive any specific grant from funding agencies in the public, commercial or not-for-profit sectors.

\section{Author contributions}

All authors contributed toward data analysis, drafting and revising the paper and agree to be accountable for all aspects of the work.

\section{Disclosure}

The authors report no conflicts of interest in this work.

\section{References}

1. World Health Organization [webpage on the Internet]. Cardiovascular Diseases (CVDs). 2017. Available from: http://www.who.int/mediacentre/factsheets/fs317/en/. Accessed November 2, 2017.

2. Smith SC, Collins A, Ferrari R, et al. Our time: a call to save preventable death from cardiovascular disease (heart disease and stroke). Circulation. 2012;126(23):2769-2775.

3. Laslett LJ, Alagona P, Clark BA, et al. The worldwide environment of cardiovascular disease: prevalence, diagnosis, therapy, and policy issues: a report from the American college of cardiology. J Am Coll Cardiol. 2012;60(25):S1-S49.

4. Tytel B, Callahan K. Shifting Paradigm: How the BRICSAre Reshaping Global Health and Development. New York: Global Health Strategies Initiative; 2012.

5. Saquib N, Saquib J, Ahmed T, Khanam MA, Cullen MR. Cardiovascular diseases and type 2 diabetes in Bangladesh: a systematic review and meta-analysis of studies between 1995 and 2010. BMC Public Health. 2012;12:434.

6. Karar ZA, Alam N, Streatfield PK. Epidemiological transition in rural Bangladesh, 1986-2006. Glob Health Action. 2009;2:1904.

7. Laskar SI. Urbanization in Bangladesh: some contemporary observations. Bangladesh Dev Stud. 1996;24(1-2):207-216.

8. Misra A, Misra R, Wijesuriya M, Banerjee D. The metabolic syndrome in South Asians: continuing escalation and possible solutions. Indian J Med Res. 2007;125(3):345-354.

9. Zaman MM, Ahmed J, Choudhury SR, Numan SM, Parvin K, Islam MS. Prevalence of ischemic heart disease in a rural population of Bangladesh. Indian Heart J. 2007;59(3):239-241.

10. Sayeed MA, Mahtab H, Sayeed S, Begum T, Khanam PA, Banu A. Prevalence and risk factors of coronary heart disease in a rural population of Bangladesh. Ibrahim Med Coll J. 2010;4(2):37-43.

11. Parr JD, Lindeboom W, Khanam MA, Koehlmoos TL. Diagnosis of chronic conditions with modifiable lifestyle risk factors in selected urban and rural areas of Bangladesh and sociodemographic variability therein. BMC Health Serv Res. 2011;11(1):309.

12. Van Minh H, Ng N, Juvekar S, et al. Self-reported prevalence of chronic diseases and their relation to selected sociodemographic variables: a study in INDEPTH Asian sites, 2005. Prev Chronic Dis. 2008;5(3):A86.

13. Turin TC, Shahana N, Wangchuk LZ, et al. Burden of cardio-and cerebro-vascular diseases and the conventional risk factors in South Asian population. Glob Heart. 2013;8(2):121-130.

14. Al Mamun M, Rumana N, Pervin K, et al. Emerging burden of cardiovascular diseases in Bangladesh. J Atheroscler Thromb. 2016;23(4):365-375.
15. Munn Z, Moola S, Riitano D, Lisy K. The development of a critical appraisal tool for use in systematic reviews addressing questions of prevalence. Int J Health Policy Manag. 2014;3(3):123-128.

16. Munn Z, Moola S, Lisy K, Riitano D. The Systematic Review of Prevalence and Incidence Data, The Joanna Briggs Institute Reviewer's Manual 2014. Australia: The Joanna Briggs Institute; 2014.

17. Riley RD, Higgins JP, Deeks JJ. Interpretation of random effects metaanalyses. BMJ. 2011;342:d549.

18. Higgins JP, Thompson SG, Deeks JJ, Altman DG. Measuring inconsistency in meta-analyses. BMJ. 2003;327(7414):557.

19. Higgins J, Thompson SG. Quantifying heterogeneity in a meta analysis. Stat Med. 2002;21(11):1539-1558.

20. Mohammad QD, Habib M, Hoque A, et al. Prevalence of stroke above forty years. Mymensingh Med J. 2011;20(4):640-644.

21. Ahmed S, Shirin S, Mohsena M, et al. Geriatric health problems in a rural community of Bangladesh. Ibrahim Med College J. 2007;1(2):17-20.

22. Zaman MM, Choudhury SR, Ahmed J, Hussain SM, Sobhan SM, Turin TC. Prevalence of stroke in a rural population of Bangladesh. Glob Heart. 2015;10(4):333-334.

23. Malik A. Congenital and acquired heart diseases: (a survey of 7062 persons). Bangladesh Med Res Counc Bull. 1976;2(2):115-119.

24. Ahsan SA, Haque KS, Salman M, et al. Detection of ischemic heart disease with risk factors in different categories of employees of university grants commission. Univ Heart J. 2009;5(1):20-23.

25. Basri R, Shaik MM, Alam MK, Mondol MB, Mohammad QD, Gan SH. Waist to hip ratio, waist to height ratio and body mass index predict stroke risk in a Bangladeshi population. Int Med J.2013;20(6):740-743.

26. Rahman F, Salman M, Akhter N, et al. Pattern of congenital heart diseases. Mymensingh Med J. 2012;21(2):246-250.

27. Khanam MA, Streatfield PK, Kabir ZN, Qiu C, Cornelius C, Wahlin $\AA$. Prevalence and patterns of multimorbidity among elderly people in rural Bangladesh: a cross-sectional study. J Health Popul Nutr. 2011;29(4):406-414.

28. Cravedi P, Sharma SK, Bravo RF, et al. Preventing renal and cardiovascular risk by renal function assessment: insights from a crosssectional study in low-income countries and the USA. BMJ Open. 2012;2(5):e001357.

29. Harbord RM, Higgins JPT. Meta-regression in stata. Stata J. 2008;8:493-519.

30. Masjedi S, Ferdous Z. Understanding the role of sex in heart valve and major vascular diseases. Cardiovasc Eng Technol. 2015;6(3):209-219.

31. Redfield MM, Jacobsen SJ, Borlaug BA, Rodeheffer RJ, Kass DA. Ageand gender-related ventricular-vascular stiffening: a community-based study. Circulation. 2005;112(15):2254-2262.

32. Möller-Leimkühler AM. Gender differences in cardiovascular disease and comorbid depression. Dialogues Clin Neurosci. 2007;9(1):71.

33. Chadha SL, Gopinath N, Shekhawat S. Urban-rural differences in the prevalence of coronary heart disease and its risk factors in Delhi. Bull World Health Organ. 1997;75(1):31.

34. Wong ND. Epidemiological studies of CHD and the evolution of preventive cardiology. Nat Rev Cardiol. 2014;11(5):276.

35. Duval S, Tweedie R. Trim and fill: a simple funnel-plot-based method of testing and adjusting for publication bias in meta-analysis. Biometrics. 2000;56:455-463.

36. Duval S, Tweedie RL. A nonparametric 'Trim and Fill' method of accounting for publication bias in meta-analysis. J Am Stat Soc. 2000;95:89-98.

37. Peters JL, Sutton AJ, Jones DR, Abrams KR, Rushton L. Performance of the trim and fill method in the presence of publication bias and between-study heterogeneity. Stat Med. 2007;26(25):4544-4562.

38. Gupta R, Joshi P, Mohan V, Reddy KS, Yusuf S. Epidemiology and causation of coronary heart disease and stroke in India. Heart. 2008;94(1):16-26.

39. Aziz KU, Faruqui A, Patel N, Jaffery H. Prevalence and awareness of cardiovascular disease including life styles in a lower middle class urban community in an Asian country. Pak Heart J. 2008;41(3-4):11-20. 
40. Chang T, Gajasinghe S, Arambepola C. Prevalence of stroke and its risk factors in urban Sri Lanka. Stroke. 2015;46(10):2965-2968.

41. Katulanda P, Liyanage IK, Caldera R, Constantine GR, Sheriff R, Mathews D. Prevalence of ischaemic heart disease and its risk factors in Sri Lanka. Ceylon Med J. 2010;55(suppl 1):53.

42. Vaidya A. Prevalence of Coronary Heart Disease in the Urban Adult Males of Eastern Nepal: A Population-Based Analytical Cross-Sectional Study [Doctoral dissertation]. Department of Biochemistry, BP Koirala Institute of Health Sciences; 2009.

43. Maskey A, Sayami A, Pandey MR. Coronary artery disease: an emerging epidemic in Nepal. J Nepal Med Assoc. 2003;42(146):122-124.

44. Anand SS, Yusuf S, Vuksan V, et al. Differences in risk factors, atherosclerosis, and cardiovascular disease between ethnic groups in Canada: the Study of Health Assessment and Risk in Ethnic groups (SHARE) Lancet. 2000;356(9226):279-284.
45. Low WY, Lee YK, Samy AL. Non-communicable diseases in the Asia-Pacific region: prevalence, risk factors and community-based prevention. Int J Occup Med Environ Health. 2015;28(1):20-26.

46. Misra A, Khurana L. The metabolic syndrome in South Asians: epidemiology, determinants, and prevention. Metab Syndr Relat Disord. 2009;7(6):497-514.

47. Sameh E-S, Karar Zunaid A, Tracey LPK, Michael ME [webpage on the Internet]. Tackling Noncommunicable Diseases in Bangladesh: Now Is the Time (English). Washington DC: World Bank; 2013. Available from: http://documents.worldbank.org/curated/en/161821468209952095/ Tackling-noncommunicable-diseases-in-Bangladesh-now-is-the-time. Accessed January 26, 2018.
Vascular Health and Risk Management

\section{Publish your work in this journal}

Vascular Health and Risk Management is an international, peerreviewed journal of therapeutics and risk management, focusing on concise rapid reporting of clinical studies on the processes involved in the maintenance of vascular health; the monitoring, prevention and treatment of vascular disease and its sequelae; and the involvement of

\section{Dovepress}

metabolic disorders, particularly diabetes. This journal is indexed on PubMed Central and MedLine. The manuscript management system is completely online and includes a very quick and fair peer-review system, which is all easy to use. Visit http://www.dovepress.com/ testimonials.php to read real quotes from published authors. 